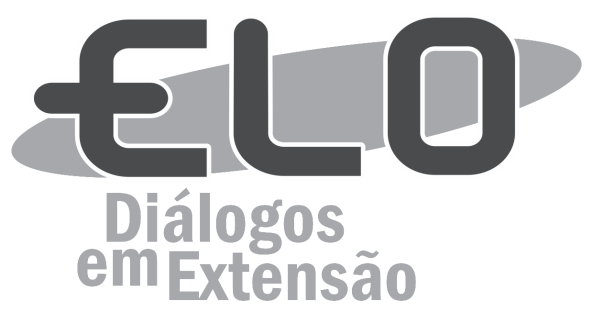

\title{
Aproximações entre extensão universitária e direitos humanos: análise a partir de uma experiência da Assessoria Jurídica Universitária Popular da UFV
}

Carlos Alberto Esteves ${ }^{1}$, Bruna Franceschini², Davi Augusto Santana de Lelis ${ }^{3}$

\begin{abstract}
Resumo: A relação entre direitos humanos e extensão universitária é retratada no presente trabalho a partir de uma experiência da Assessoria Jurídica Universitária Popular da Universidade Federal de Viçosa (AJUP/ UFV), qual seja, o diagnóstico do padrão de violação de direitos fundamentais decorrentes da construção da Pequena Central Hidrelétrica de Fumaça, no Sudeste do Estado de Minas Gerais. Para se levar a efeito tal proposta, foi essencial o vinculo criado entre a AJUP/UFV, o Movimento dos Atingidos por Barragens (MAB) e os moradores da comunidade atingida com a construção daquele empreendimento. Partindo de metodologias horizontalizadas, cujo foco consiste em promover um trabalho de assessoria em detrimento da ideia de assistência jurídica, pôde-se vislumbrar o quão virtuosa se revelou tal estratégia, na medida em que permitiu a construção de conhecimento emancipatório, produto do diálogo entre as esferas acadêmica e popular.
\end{abstract}

Palavras-chave: Direitos Humanos. Extensão Universitária. Assessoria Jurídica Universitária Popular. Emancipação.

Área Temática: Direitos Humanos, Teorias e Metodologias em Extensão e Políticas Públicas.

\section{An approach between university extension and human rights: an analisis through the Popular University Assessorship experience at Federal University of Viçosa.}

\begin{abstract}
The relation between Human Rights and University Extension is demonstrated in the present work through an experience of Popular University Legal Assessorship, at Federal University of Viçosa (AJUP (UFV), which task was to diagnose the fundamental rights violation pattern in consequence of the construction of the Small Hydroelectric Central, in the city of Fumaça, southeastern Minas Gerais state. To accomplish the study, there was an essential link among the institution AJUP / UFV, the social movement of people affected by the hydroelectric constructions, which name, in Portuguese, is "Movimento dos Atingidos por Barragens" $(M A B)$ and the residents of the envolved community. Based on the ideia of horizontal methodologies, the focus was to promote an accessorial work instead of the traditional ideia of regular legal assistance. This strategy has revealed itself very virtuous once it allowed an emancipatory knowledge construction coming from the dialogue between academic and popular spheres.
\end{abstract}

Keywords: Human Rights. University Extension. Popular University Legal Assessorship. Emancipation.

Thematic areas: Education and Culture.

\footnotetext{
${ }^{1}$ Professor substituto do Departamento de Direito da Universidade Federal de Viçosa. E-mail: carlos.esteves@ufv.br

${ }^{2}$ Mestranda em Ciências Jurídico - Políticas, com menção em Direito Constitucional, pela Universidade de Coimbra, Portugal. E-mail: franceschini.bruna@gmail.com ${ }^{3}$ Professor Auxiliar do Departamento de Direito da Universidade Federal de Viçosa, doutorando em direito público pela Pontifícia Universidade Católica de Minas

Gerais, bolsista da CAPES. E-mail: davilelis@ufv.br
} 


\section{Aproximaciones entre la extensión universitaria y los derechos humanos: análisis desde una experiencia de la Asesoria Juridica Universitaria Popular de la UFV.}

Resumen: La relación entre los derechos humanos y la extensión universitaria está retratada en el presente trabajo a partir de una experiencia de la Asesoría Universitaria Jurídica Popular de la Universidade Federal de Viçosa (AJUP/UFV), constituyéndose en el diagnóstico del estándar de la violación de los derechos fundamentales originados de la construcción de la Pequeña Central Hidroeléctrica de Fumaça, en el Sudeste del Estado de Minas Gerais. Para llevarse a cabo tal propuesta, ha sido imprescindible el vínculo creado entre la AJUP/UFV, el Movimiento de los Afectados por las Presas de Agua (MAB) y la población de la comunidad afectada con la construcción de dicho emprendimiento. A contar de metodologías horizontales, cuyo foco consiste en la promoción de un trabajo de asesoría en detrimento de la idea de asistencia jurídica, se ha podido vislumbrar lo cuanto eficaz se ha presentado tal estrategia, al paso que se ha permitido la construcción del conocimiento emancipador, producto del diálogo entre las esferas académica y popular.

Palabras clave: Derechos Humanos. Extensión Universitaria. Asesoría Jurídica Universitaria Popular. Emancipación.

\section{Introdução}

A Constituição Federal previu em seu texto, artigo 207, que as universidades deveriam atender ao princípio indissociável de ensino, pesquisa e extensão (BRASIL, 2012). Priorizar cada um destes eixos é, no que diz respeito ao ensino superior, o norte a ser seguido. A forma como cada um desses eixos é abordada implica tanto na formação de estudantes, profissionais e cidadãos, como no conhecimento produzido pelo país; influenciando a sociedade como um todo e, ao mesmo tempo, sofrendo o influxo do modelo econômico e ideológico majoritário de sua época. Por esses motivos, entende-se que atualmente a educação, no tripé principiológico constitucional, acaba por escancarar os reflexos científicos, políticos e sociais de uma lógica capitalista, não apenas seguindo os moldes já concebidos e conhecidos sem questioná-los, mas sim, desvelando contradições para ser o agente da mudança que se pretende.

Como objeto específico deste trabalho, toma-se a Assessoria Jurídica Popular (AJUP) como parte importante da atividade extensionista. Primeiramente, dar-se-á enfoque à extensão universitária, a qual se fundamenta na concepção de conhecimento, explicitando-se como as atividades deste eixo são tradicionalmente praticadas e como é possível vislumbrar novas maneiras de estender à população o conhecimento produzido nos centros universitários.

Importa, então, contextualizar as AJUP sob um novo ponto de vista extensionista. As AJUP, surgidas nos anos 1950, podem ter como sua área de atuação inúmeras esferas da sociedade, de molde a atuar, sempre, a partir de uma perspectiva interdisciplinar. A AJUP, no contexto dos cursos de Direito, é o contraponto aos habituais escritórios modelos e núcleos de prática jurídica, recorrentemente, presentes nas universidades.

Na Universidade Federal de Viçosa (UFV), a AJUP ${ }^{4}$ participou ativamente na defesa de direitos da população atingida pela construção da Pequena Hidrelétrica de Fumaça (PCH Fumaça), localizada entre os municípios mineiros de Diogo Vasconcelos e Mariana, em Minas Gerais. Os resultados dessa ação, expostos nesse trabalho, foram encorajadores para a AJUP-UFV almejar novos projetos e pretender se tornar referência neste movimento extensionista inovador, cujas características são melhor apresentadas adiante.

\section{O novo paradigma da extensão universitária}

O conhecimento é a ferramenta cotidiana da comunidade universitária, (estudantes, extensionistas e pesquisadores), motivo pelo qual a forma de compreensão desse instrumento aludirá diferentes atuações. Com base em Lelis, Coelho e Dias, (2012), inicia-se o estudo sobre o conhecimento remetendose a Platão. Para os autores, com a Alegoria da Caverna, (PLATÃO, 1989, p.52), o filósofo grego traz à tona a indagação de que as pessoas, desprovidas do conhecimento, seriam condenadas a viver apenas de ilusões, ignorando a realidade que os cerca. Quem, por ventura, tomasse conhecimento da 
realidade, compreenderia o conhecimento, abandonando as falsas verdades até então apreendidas. Deste mito, extrai-se a correlação entre a percepção das coisas e a própria linguagem como frutos de uma relação social dentro de uma coletividade.

Adiante, as ponderações sobre o conhecimento passaram pelo período medieval, enquanto uma revelação divina e incumbência da Igreja, sendo superada, todavia, no século XVII, com o saber científico. Nesse momento, há destaque para dois pensadores: Descartes, que, acreditando na dúvida como fruto do conhecimento, tinha como foco a formação de mentes e acreditava na ciência por si só, com ênfase para o indivíduo (DESCARTES, 2010); e Bacon, que, percebendo o conhecimento como produto do empirismo, objetivava, a partir deste, o controle e modificação da natureza, além de almejar uma ciência coletiva (BACON, 1989). Os iluministas, bebendo da água desses fundadores do conhecimento científico, fracionaram o saber e vangloriaram a racionalidade com o fim maior de um bem estar geral, com fulcro na liberdade, igualdade e fraternidade (LELIS; COELHO; DIAS, 2012, p.71).

O século XIX inaugura o positivismo, a prática que enalteceu a técnica com fins de produção industrial, reforçando o ideário capitalista da época. Com isso, naturalizou-se o processo de mitigar inflexões críticas e esclarecedoras, e enalteceu-se o processo primordialmente produtivo, em que se correlacionaram técnica (ciência) e indústria; o que favoreceu o processo de exploração do homem pelo próprio homem. Morin (2005, p. 109) esclarece que:

[...] o desenvolvimento da técnica não provoca somente processos de emancipação, mas também novos processos de manipulação do homem pelo homem ou dos indivíduos humanos pelas entidades sociais. [...] A sujeição signiûca que o sujeito sujeitado sempre julga que trabalha para seus próprios ûns, desconhecendo que, na realidade, trabalha para os ûns daquele que o sujeita. Assim, efetivamente, o carneiro-chefe do rebanho julga que continua a comandar seu rebanho, quando, na realidade, obedece ao pastor e, ûnalmente, à lógica do matadouro.

Explanado este panorama de concepção do conhecimento, percebe-se a extensão inserida na vigente lógica de conhecimento e economia: há regência de paradigmas do individualismo e do tecnicismo, num processo vertical de transmissão do conhecimento, em que há sujeitos ativos, que levam conhecimento técnico-científico (produtivo) e há sujeitos passivos, que recebem os conhecimentos; de maneira que a atividade extensionista é mero marco na desvalorização do saber popular, porque pretende negá-lo e substituí-lo por um saber tecnológico a serviço do capital. No Brasil, um país, essencialmente agrário, a extensão rural evidenciou tudo que até agora foi exposto. Acepção confirmada por Coelho (2005, p. 71), pois:

O trabalho de assistência técnica da Extensão Rural no Brasil era um projeto educativo para o capital (industrial e ûnanceiro). [...] Por isso, a idéia de transferir certos traços de 'cultura' e recursos de uma condição social considerada mais avançada (a sociedade urbana e industrial) para outros espaços sociais considerados atrasados (o espaço agrário) foi, e para alguns ainda é, um equívoco baseado na prepotência camuûada de 'boa vontade' ou voluntarismo autoritário.

Dessa maneira, a extensão seria mera invasão do espaço do outro, um desrespeito ao que as comunidades apreendem como interessante para elas próprias. Nega-se a capacidade transformadora dos sujeitos passivos, não havendo como construir um conhecimento verdadeiramente autêntico. Será Freire (2006), quem irá apresentar formas de romper com o tecnicismo, com o preconceito de que existem sujeitos passivos coisificados na sociedade, e com a aplicação de um conhecimento hierarquizado das universidades, detentoras do saber, para as populações às suas margens. Em suas palavras: 
Educar e educar-se, na prática da liberdade, não é estender algo desde a 'sede do saber', até a 'sede da ignorância' para 'salvar', com este saber, os que habitam nesta. Ao contrário, educar e educarse, na prática da liberdade é tarefa daqueles que sabem que pouco sabem - por isto sabem que sabem algo e podem assim chegar a saber mais - em diálogo com aqueles que, quase sempre, pensam que nada sabem, para que estes, transformando seu pensar que nada sabem em saber que pouco sabem, possam igualmente saber mais. (FREIRE, 2006, p. 25.)

A proposta da AJUP para a educação popular adota exatamente o que Freire propõe: o entendimento de que o conhecimento se produz de uma maneira horizontal, sem que existam sujeitos ativos e passivos, sendo possível promover constantemente troca de experiências e saberes em que todos possam ser ao mesmo tempo atuantes.

O panorama tradicional da extensão tem uma concepção de mera prestação de serviços. Contudo, dadas as críticas feitas a esse modelo, há que se mudar a perspectiva: extensão não é, nem deve ser, invasão, desrespeito e destruição da sabedoria do outro, tampouco mero serviço. A extensão deve ter o cunho de emancipação, troca de aprendizados, construção coletiva e, mais importante, ter o condão de efetivar direitos fundamentais.

Em análise da extensão rural, que representa o aqui exposto, Lelis, Coelho e Dias (2012, p. 78), propõem a inversão da ótica posta, de modo que a extensão deixa de:

(...) privilegiar a mera transferência de tecnologia, para privilegiar a execução de projetos e programas que elevem a condição inicial do projeto iluminista para, enfim, promover a igualdade, a emancipação social e o bem estar da coletividade sob os pilares de direitos fundamentais.

Tem-se firme o porto de que a extensão deve ser um veículo para direitos fundamentais, fazendo com que o Estado seja o garantidor desses direitos. Assim, os cidadãos que receberem os assessores, terão meios legais de exigir o que a própria constituição já havia lhes garantido: liberdade, igualdade e fraternidade (LELIS; COELHO; DIAS, 2012, p. 79).

\section{As assessorias jurídicas populares sob a nova perspectiva da extensão}

Tradicionalmente, a prática da extensão, nos cursos de Direito, ocorre por meio dos escritóriosmodelos, que priorizam aspectos jurídicos e processuais individuais em detrimento de aspectos jurídico sociais. Esse modelo fortalece o individualismo e concretiza a lógica de prestação de serviços que muitos atribuem à extensão (ABRÃO, et all, 2009).

Mas, pelo exposto, entende-se que a prática da extensão nos cursos de Direito deveria possibilitar a emancipação dos estudantes desse modelo tradicional, proporcionando a eles uma adequação entre seus conhecimentos jurídicos com a realidade social em que estiverem inseridos. Seguindo as reflexões de Gustin (2006, p. 61):

O estudante e o docente dos cursos de Direito não devem ser sujeitos conformados apenas aos conteúdos procedimentais teóricos estatuídos, mas sim, às potencialidades de crítica do próprio ensino quando este não possuir instrumentos capazes de tornar o estudante preparado para ter consciência da complexidade que o cerca e competência para decodificá-la de forma sensível e humana.

Expostas estas críticas ao modelo extensionista existente e, também já delineados os contornos de uma atividade emancipatória, as AJUP desabrocham como a alternativa tão procurada de uma 
prática jurídica popular livre, desapegada de questões positivistas e de neutralidade; pois as AJUP possibilitam práticas relacionadas às causas coletivas e sociais, com o objetivo de empoderamento ${ }^{5}$ das comunidades. No que versa a esse modelo transformador de extensão, estão os ensinamentos de Abrão et al (2009, p. 443):

Por outro viés, a prática extensionista inovadora, que se pretende tanto mais democrática quanto promotora do acesso à justiça em seu sentido mais amplo, pauta-se pelo estabelecimento de uma interlocução de saberes de forma relacional, circular e horizontal, equiparando os sujeitos partícipes desta relação. Deste modo, o que se dá é um processo de construção do conhecimento (em contraposição à transmissão), fundado na perspectiva autônomoemancipatória das relações humanas, fomentando o que Morin denomina de "religação de saberes"..

Inicialmente, é necessário revelar que as AJUP podem se concretizar dentro das universidades, em caráter interdisciplinar, com estudantes e professores. Mas também existem fora do mundo universitário, em que os profissionais do Direito, de movimentos sociais, de sindicatos, de organizações não governamentais, entre outros, mantém-se em atividade nas práticas de cunho popular e coletivo ao efetivar as teorias de um Direito $\mathrm{Crítico}^{6}$. Com isso, é de se verificar que as AJUP são, na verdade, um movimento jurídico que possibilita ações jurídicas em caráter transformador, mas que ainda clamam por produções acadêmicas a fim de clareá-las (MAIA, 2006).

A espinha dorsal deste movimento é a questão da emancipação e do empoderamento, em que o Direito é abordado pelo seu viés transformador e revolucionário, cujo objetivo será a promoção dos direitos fundamentais; pois a essência da AJUP está na:

[...] abordagem emancipatória em que baseia suas ações e no fundamento do Direito entendido como instrumento de transformação social, bem como no compromisso do assessor jurídico popular com a luta das classes populares em defesa e promoção dos direitos humanos e fundamentais, por uma sociedade mais justa, mais igual e mais humana (MAIA, 2006, p.18).

O Estado Democrático de Direito tem por fundamento a legitimação do pluralismo jurídico ${ }^{7}$. Ao lado deste conceito, acresce-se que se pode conceber o atual momento como reflexo da terceira onda de acesso à justiça ${ }^{8}$, a qual preconiza a utilização de métodos alternativos de composição de conflitos, bem como o desenvolvimento de práticas jurídicas inovadoras. Compreende-se desses elementos que a prática das AJUP serve para legitimar não somente o trabalho dos grupos envolvidos, mas também o fundamento jurídico e social do próprio Estado de Direito. (ABRÃO et al, 2009, p.436).

Campilongo, apud Maia, (2006, p.86), aponta as características das assessorias jurídicas populares: atuar em pautas coletivas; demandar ações de impacto social; promover a emancipação humana e a participação dos litigantes; romper com a mística ${ }^{9}$ que envolve o Direito; favorecer a explosão dos litígios; facilitar acesso à justiça; ser interdisciplinar; levar a efeito a ética comunitária ${ }^{10}$; e, finalmente, alcançar a justiça. Todas essas ações, pautadas em verdadeiro diálogo entre as partes e tendo em vista a promoção do acesso aos direitos fundamentais, constituem a base principiológica de uma extensão inovadora no âmbito dos cursos de Direito.

\section{Assessorias Jurídicas Populares e os Escritórios Modelos}

Os escritórios modelos se enquadram na ideia de serviços legais tradicionais e se contrapõem às AJUP, uma vez que têm como finalidades atuar em pautas individuais; focar nas demandas judiciais; praticar ações assistencialistas; contar com a apatia dos litigantes e com a sacralização ${ }^{11}$ do Direito; controlar a litigiosidade; promover um acesso ao Judiciário - e não à justiça, necessariamente -, seguir os moldes de uma advocacia tradicional pautada na ética utilitária ${ }^{12}$ e buscar uma certeza jurídica, muitas vezes em detrimento da justiça (CAMPILONGO apud MAIA, 2006, p.86). 
É Abrão et al, (2009) quem propõe os elementos para distinguir os dois modelos. São eles: a metodologia utilizada, o objetivo e o fundamento ideológico. Na assistência judiciária, no que tange à metodologia, depara-se com tutelas individuais, em relações hierarquizadas, em que os não detentores do saber jurídico se mantêm inertes. Sobre os objetivos, nos escritórios modelos, como próprio nome já induz, há uma prestação de serviço, simplesmente. Por fim, ideologicamente, reforça-se a questão do individualismo.

A assessoria jurídica, por sua vez, estabelece metodologias de relações horizontais, as quais proporcionam o protagonismo tanto dos assessores, quanto da comunidade. O objetivo é o empoderamento e a emancipação, por intermédio de uma educação cidadã. E, por último, a ideologia perpassa a ideia de uma ética solidária, palpável pela organização coletiva.

Assim, embora o modelo clássico acabe por garantir direitos, são nas AJUP, nos moldes de extensão propostos, que os direitos são garantidos em um diálogo entre os sujeitos que necessitam de empoderamento e os assessores, estes detentores do conhecimento técnico-formal.

\title{
Breve Histórico das Assessorias Jurídicas Populares
}

A assessoria estudantil data da década de 1950, com o oferecimento de assistência jurídica gratuita pelo Serviço de Assistência Jurídica Gratuita (SAJU) da Universidade Federal do Rio Grande do Sul (UFRGS). Esta foi a inspiração para a propagação de diversos núcleos de práticas e escritórios modelos nos anos que se passaram. Porém, só aquele primeiro teve relevante atuação, até ser fechado, durante os anos de repreensão militar (RIBAS, 2008, p.247).

Os anos 1980, ainda em épocas de regime ditatorial, marcaram um esvaziamento do modelo assistencialista de extensão em Direito, e no fim da década, a nomenclatura, serviços legais inovadores, se consolidou como a utilização de meios oficiais e não oficiais para o acesso à justiça. Antes dessa nomenclatura foram expressões de tais serviços: Gabinete de Assessoria Jurídica às Organizações Populares (GAJOP), de Olinda; a Associação de Advogados de Trabalhadores Rurais (AATR), em Salvador; a Rede Nacional de Advogados e Advogadas Populares (RENAAP), em âmbito nacional; Acesso Cidadania e Direitos Humanos, de Porto Alegre; e, ainda, o escritório Terra de Direitos em Curitiba (RIBAS, 2008, p.251).

A década de 1990 é marcada por esparsas movimentações sobre a redemocratização, a discussão da reforma agrária e da efetivação dos direitos humanos, mas evidenciando a dificuldade de articulação e de rompimento da apatia instaurados nos anos ditatoriais (RIBAS, 2008, p.248).

Nesse contexto, necessário esclarecer as tentativas de se teorizar e de se utilizar nomenclaturas uniformes para tratar do tema a partir de então. Segundo Luz, haveria que se conceber duas formas de assessoria: a universitária e a advocacia popular. Ribas propõe três modelos de assessoria: a advocacia popular, a exemplo da RENAAP e Terra de Direitos; a assessoria universitária que se pauta pela troca de conhecimento popular e incrustada na interdisciplinariedade, como o projeto Pólos de Cidadania da UFMG; e, como espécie dessa última, a assessoria estudantil com o protagonismo estudantil interdisciplinar, com autonomia em relação às instituições de ensino superior, por exemplo o SAJURS (ligado à UFRGS), Najup - RS (autônomo) e a RENAJU (RIBAS, 2008, p.253).

A época ainda marcava a correlação entre as assessorias e os movimentos estudantis, com encontros regionais e a existência de uma Coordenação Nacional de Assessoria Jurídicas Universitárias (CONAJU):

\begin{abstract}
A noção de assessoria, na época, estava ligada à idéia de "apoio jurídico popular", como "uma prática de vanguarda ainda praticamente inédita e que significa, entre outros, um remodelamento das relações estabelecidas entre o profissional do Direito e a clientela que bate à sua porta diariamente". A assessoria já estava ligada, timidamente, a educação popular, pluralismo jurídico, cidadania. (RIBAS, 2008, p. 248)
\end{abstract}

Nos idos de 1996, as assessorias da Universidade Federal da Bahia (UFBA) e da UFRGS fundaram a Rede Nacional de Assessoria Jurídica Universitária (RENAJU). Até hoje a RENAJU é referência no meio das assessorias, organizando-se em âmbito nacional, regional e local (RIBAS, 2008, p.248). Como 
alento, observa-se nesses, nos encontros promovidos por esta Rede, o crescente número de pessoas, sejam de cursos diversos, sejam de cursos de Direito, trabalhando no modelo de extensão dialógica e garantidora de direitos.

Além das fronteiras brasileiras, também se evidenciam movimentos populares que clamam por direitos, como é o caso da Colômbia, Chile e Argentina. Em especial, o Instituto Latinoamericano de Servicios Legales Alternativos (ILSA), que publica a revista El Outro Derecho, na Colombia; o Centro de Reflección y Acción para el Cambio, o projeto Formación Jurídica para la Acción (FORJA), ambos do Chile; e, Centro de Estudios Legales y Sociales (CELS), da Argentina (RIBAS, 2008, p. 251).

$\mathrm{Na}$ Universidade Federal de Viçosa (UFV), a AJUP ainda possui trajetória recente, mas aos poucos demonstra ser efetivo instrumento de modificações sociais benéficas, por meio de suas relações dialógicas que proporcionam o protagonismo das comunidades, em um caminho de empoderamento e emancipação.

A sua consolidação como projeto de extensão da UFV, vinculada ao Observatório de Movimentos Sociais, ocorreu apenas no ano de 2012, mas foi fruto de longos anos de discussão acerca do Direito Crítico, fomentado pelo Grupo de Estudos Alternativo do Direito (GEAD), surgido no final da década de 1990. Das inquietudes trazidas pelo estudo pautado na dicotomia teoria/práxis, derivaram inserções dos participantes em atos públicos, manifestações, estágios interdisciplinares de vivência e, em especial, no processo que tentou efetivar a extinta Rede Popular dos Estudantes de Direito (REPED), com abrangência nacional, e que tinha como um dos objetivos respaldar os movimentos sociais; entre esses a AJUP. Mas, apenas em 2011, no Encontro Nacional dos Estudantes de Direito Extensionistas (ENEDex), a AJUP tornou-se prioridade na pauta dos estudantes da UFV, consolidando-se, como já dito, no ano de 2012. Atualmente a AJUP-UFV já possui atuações concretas, a exemplo do que se passou na PCH Fumaça.

\section{Pequena Central Hidrelétrica de Fumaça: um relato de experiência da AJUP-UFV}

A Pequena Central Hidrelétrica de Fumaça, ou simplesmente PCH Fumaça, foi construída no final da década de 1990, nos municípios de Diogo de Vasconcelos e de Mariana, sudeste do Estado de Minas Gerais. Sob o controle da empresa Novelis do Brasil Ltda ${ }^{13}$, de origem norte-americana, o empreendimento utiliza o potencial hidráulico das águas do Rio Gualaxo do Sul, tendo por objetivo a produção de energia elétrica para realizações exclusivamente privadas, já que visa a abastecer outros empreendimentos do respectivo grupo empresarial.

Em razão da construção da barragem, o que pressupõe o alagamento de grande extensão territorial, várias comunidades da região foram atingidas, totalizando cerca de 600 pessoas, todas elas, de alguma forma, dependentes da terra para sustento próprio e de suas famílias. Neste cenário, camponeses, extrativistas, artesãos, meeiros e diaristas se organizaram junto ao Movimento dos Atingidos por Barragens $(\mathrm{MAB})^{14}$, na tentativa de se mobilizarem e de resistirem aos abusos cometidos durante o processo de implantação e de operação do empreendimento.

Ainda durante o período de construção da barragem, a empresa não reconheceu grande parte das famílias que seriam atingidas com o alagamento da região. Somente após diversas manifestações que culminaram com duas ocupações do canteiro de obras da $\mathrm{PCH}$, é que a maioria (frise-se, não a totalidade) dos atingidos conquistou seu reconhecimento ${ }^{15}$.

A Assessoria Jurídica Universitária Popular da Universidade Federal de Viçosa (AJUP-UFV) inseriu-se, a partir do ano de 2012, nesse processo com a missão de elaborar um relatório detalhado dos possíveis direitos humanos violados com a implantação da $\mathrm{PCH}$ Fumaça. A finalidade precisa desse relatório foi realizar, com base em provas coletadas a partir do diálogo com as comunidades, um levantamento de todas as afrontas à dignidade da pessoa humana e ao meio ambiente, de molde a subsidiar a intervenção do Ministério Público Federal (MPF), órgão que já havia, inclusive, instaurado Inquérito Civil com vistas a apurar as irregularidades e os abusos cometidos pela empresa responsável.

Juntamente com os militantes do MAB e com os moradores, os membros da AJUP-UFV deram continuidade ao trabalho de análises das apurações já levantadas pelo Inquérito Civil instaurado pelo MPF, bem como da coleta de informações e de provas que pudessem lastrear eventual ajuizamento de ação judicial. Neste contexto, ao longo dos meses de maio a julho de 2012, foram realizadas 94 entrevistas, as quais continham um roteiro definido: a) caracterização da família e das atividades 
desenvolvidas por cada uma delas; b) estudo da influência do empreendimento nestas atividades; c) pesquisa do modo como se processaram as negociações das perdas decorrentes do alagamento da área; d) percepção de cada família sobre o empreendimento.

De posse das referidas entrevistas, foi possível sistematizar, em classes ${ }^{16}$, as violações e/ou ameaças aos direitos humanos em razão das condutas do empreendedor.

Pôde-se perceber que houve afronta ao Direito à livre negociação e ao tratamento isonômico. Vários entrevistados realçaram que, durante o processo de instalação da $\mathrm{PCH}$, a empresa enviou prepostos que os constrangeram a aceitar a negociação da forma que mais favorecia ao empreendimento e que mais degradava as condições vida da população. Como resultado, uma negociação que deveria ter se realizado coletivamente, acabou por ter sido levada a efeito de forma individual, fato que comprometeu a isonomia no que diz respeito ao tratamento dispensado às famílias.

Ademais, na maioria das vezes, apenas foi ofertada à população a possibilidade de receberem a indenização em espécie - de valor insuficiente. A empresa praticamente desconsiderou as hipóteses de permuta de terras ou de reassentamento, possibilidades estas preconizadas pela Lei n. 12.812/98 do Estado de Minas Gerais.

A segunda violação constatada relaciona-se ao direito à plena reparação de perdas e ao direito ao trabalho, uma vez que vários profissionais da região, que dependiam da terra e demais recursos naturais para realizarem suas atividades, não foram devidamente ressarcidos. Meeiros, areeiros, garimpeiros, artesãos, diaristas e proprietários receberam indenizações cujos valores estavam aquém dos prejuízos efetivamente sofridos, já que nem mesmo se considerou, para efeitos de cálculos de ressarcimento, as perdas das benfeitorias produtivas, como rochas, areias, jazidas de pedra sabão e, sobretudo, terras férteis que se situavam nas margens do rio.

Aqueles que puderam optar pelo reassentamento convivem com o drama de não serem os reais proprietários da terra que habitam. Tal fato traz consigo uma série de implicações, como a insegurança jurídica e o impedimento de inserção em programas governamentais (a exemplo do PRONAF, do Crédito Rural e do Programa de Aquisição de Alimentos), ou mesmo de realização de empréstimos bancários.

Impedidos de realizarem as atividades que outrora desempenhavam, muitos trabalhadores saíram do meio rural em busca de melhores condições de vida nas cidades vizinhas. Em meio ao ambiente urbano de Belo Horizonte, Mariana e Ouro Preto, o resultado não podia ser outro: considerando que a maioria desses emigrantes trabalhava exclusivamente com a terra e possuíam pouca qualificação formal, a maioria permanece desempregada, sofrendo com o processo de marginalização típico dos grandes centros.

Os direitos culturais também foram ultrajados. O alagamento da área acabou por comprometer as fontes de pedra sabão, matéria-prima utilizada na fabricação de panelas. Esta atividade, além de constituir importante fonte de renda dos moradores de algumas comunidades, também representa importante expressão do patrimônio cultural imaterial, não apenas de cada artesão, mas da coletividade.

Ao visitar as casas da região, é possível verificar que muitas oficinas de pedra sabão encontramse desativadas, haja vista a escassez e, por isso, o alto valor com que essa matéria-prima passou a ser comercializada.

Em várias entrevistas, foi possível constatar a insatisfação dos atingidos quanto às repercussões das obras da barragem em suas casas. Aquelas localizadas próximas ao canteiro de obras tiveram suas estruturas danificadas e aquelas outras, construídas nos reassentamentos, não levaram em consideração as particularidades de cada grupo familiar. Neste particular, o empreendimento transgrediu o direito à moradia adequada.

Há relatos de que, em algumas situações, famílias foram submetidas à sobrevivência dentro de contêiner; outras tiveram suas propriedades invadidas; há, ainda, pessoas idosas que, expostas a ruídos intensos por longo período, abandonaram suas antigas casas, o que desencadeou o desenvolvimento de sérios quadros patológicos.

Os direitos a um ambiente saudável e à saúde também não foram respeitados pelo empreendedor, principalmente com relação ao distrito de Miguel Rodrigues, localizado no município de Diogo de Vasconcelos. Neste caso, duas degradações se tornaram emblemáticas: a primeira relativa às condições sanitárias do distrito, visto que, em que pese a empresa ter se responsabilizado pela construção e manutenção da Estação de Tratamento de Esgoto (ETE), esta manteve-se funcionando por curto espaço de tempo; a segunda referente ao atendimento à saúde, pois os postos de saúde construídos 
em algumas comunidades não possuíam a infraestrutura necessária para atendimento à população, razão pela qual foram reformados pela Administração Pública Municipal.

A inexistência de um cercado ao longo dos quatorze quilômetros da lagoa é um fato que igualmente compromete o direito a um espaço de vivência adequado. Conforme relato de vários membros da comunidade, não são raros os episódios de morte envolvendo moradores da região que acidentalmente caem na represa em virtude da proximidade desta com a estrada, da ausência de iluminação e de sinalização adequada, além da já citada falta de cerca envolvendo a área alagada.

No mesmo passo, o direito de ir e vir teve suas finalidades comprometidas, posto que, em decorrência da construção da barragem, várias localidades, antes facilmente acessíveis, tornaram-se ora inalcançáveis, ora de difícil acesso, seja em razão da distância, seja em virtude das condições de tráfego.

Esse comprometimento no direito de ir e vir resvalou de modo significativo na saúde de alguns idosos. Isso porque, no passado, muitos deles viviam em distritos que contavam com serviço de transporte intra e interurbano; com o alagamento da região, passaram a habitar casas localizadas em regiões de acesso tormentoso, onde não há atendimento médico, tampouco a disponibilização de transporte para o meio urbano. O resultado desse processo é a precarização das condições de vida da pessoa idosa, em razão da impossibilidade de manterem o controle efetivo das moléstias que os acometem e as cautelas que o avançar da idade exige.

Várias das violações até agora mencionadas ocorreram sem que se observassem as condições impostas nas Licenças Ambientais. Ou seja, ainda que as Licenças que autorizam a instalação e o início das operações contivessem cláusulas de tutela de vários direitos humanos, esses foram flagrantemente desrespeitados, o que revela uma verdadeira desobediência ao direito ao devido processo legal ambiental. No que diz respeito à transgressão desta garantia constitucional, as investigações do Ministério Público Federal apontam exatamente para essa irregularidade: as licenças de instalação e de operação da PCH Fumaça foram concedidas sem que tivessem sido observadas diversas condicionantes, principalmente as relacionadas aos compromissos de alcance social, o que demonstra, claramente, uma omissão do órgão licenciador em relação ao empreendimento.

Independentemente da causa, importa salientar que a concessão das Licenças ambientais sem a observância do cumprimento das condicionantes contribuiu para que a empresa levasse a efeito um projeto que, em muito, maculou a dignidade e a honra de vários homens, mulheres, idosos e crianças que possuíam, até então, tradições particulares, costumes distintos, uma vida própria. Mais uma vez, se pôde visualizar uma situação em que os interesses exclusivamente privados se sobrepuseram à vontade e à dignidade de uma coletividade.

\section{Conclusões}

Trabalhar juntamente aos atingidos pela construção da PCH Fumaça foi, decerto, uma oportunidade que contribuiu sob dois aspectos: de um lado, para se avaliar a capacidade extensionista da assistência jurídica popular e a forma como metodologias de construções coletivas do conhecimento, a partir de dinâmicas efetivamente horizontais, são plenamente realizáveis; e, de outro, para oportunizar, por meio do somatório de forças, que os prejudicados com o empreendimento tivessem voz, utilizando-se, para isso, dos mecanismos institucionais e legais que o próprio ordenamento jurídico disponibiliza em prol daqueles que tem algum direito fundamental ultrajado.

A parceria AJUP-UFV, MAB e moradores atingidos pela construção da $\mathrm{PCH}$ Fumaça viabilizou uma troca de conhecimento entre as esferas acadêmica e popular, sem que se vislumbrasse a sobreposição de um em relação ao outro. Ao revés, deste processo resultou a construção de um novo conhecimento, produto da fusão daquelas duas percepções do conhecer.

A construção desse conhecimento só se fez possível porque a comunidade atingida não foi concebida como mero objeto de investigação, ou laboratório humano passível de intervenção, tampouco a AJUP atuou como mera prestadora de serviços. O uso de espaços ampliados de participação popular, como assembleias locais, aliado às vivências dos membros da AJUP, os quais participaram efetivamente do dia a dia dos atingidos, atuando conjuntamente no diagnóstico dos direitos que lhe foram subtraídos, foram os fatores que permitiram com que esta parceria se tornasse efetivamente virtuosa. 
Dito de outra forma, o uso de metodologias horizontalizadas culminou na participação, por parte dos moradores de Fumaça, de todas as etapas dos trabalhos descritos, tornando-se esses, ao lado dos militantes do MAB e dos membros da AJUP, verdadeiros protagonistas deste processo de construção do saber.

Desse quadro, é possível inferir que a atividade extensionista protagonizada, em Fumaça, pelos atores locais e pelos membros dos movimentos sociais teve o condão de efetivar os direitos fundamentais a partir de dois enfoques.

A um primeiro olhar, fica claro que, ao pretender colaborar com a atuação do MPF, o trabalho desenvolvido favoreceu, em última análise, o acesso à justiça dos cidadãos atingidos pela construção do empreendimento. Isso porque, em virtude da violação, por parte da empresa, de todos os direitos listados anteriormente, os atingidos não podem ser desconsiderados como partes integrantes desse cenário, razão pela qual o acesso aos meios institucionalizados que lhes proporcionem reclamar seus direitos deve lhes ser garantido, sob pena de transgressão de outros direitos e garantias fundamentais.

Sob outro ângulo, ao privilegiar a troca de conhecimentos entre os atores, a metodologia utilizada serviu para concretizar a construção de um novo saber, a partir de um processo coletivo, dialógico e horizontal, que, por assim ser, projetou suas sombras para a formulação de um conhecimento essencialmente emancipatório.

A atuação em Fumaça serviu, de modo particular, para encorajar os membros da AJUP-UFV a continuarem firmes no propósito de implementar uma atuação jurídica diferenciada, cujo pano de fundo é uma atividade extensionista emancipatória e cujas bases estão fixadas no ideal constitucional de uma sociedade efetivamente justa. Que este ideário permaneça como a mola propulsora do agir. E que o horizonte, embora sempre longínquo, conserve-se como a utopia na qual se inspira; que impulsiona sempre o caminhar...

\section{Referências Bibliográficas}

ABRÃO, Rosa Maria Zaia Borges; TEIXEIRA, Christine Rondon; BRUSCATO, Giovani Tavares; RIPOLL, Joana Cavedon; PAULA, Luciana Araújo de. Limites e perspectivas da Extensão Universitária: um olhar a partir da Assessoria Jurídica Popular. In: Captura Crítica: direito, política, atualidade. Revista Discente do Curso de pós-graduação em Direiro. - n.2. v.1. (jul/dez 2009) Florianópolis, Universidade Federal de Santa Catarina, 2009. Disponível em: <http:// www.ccj.ufsc.br/capturacriptica/documents/n2v1/parciais/20.pdf>. Acesso em: 11 nov. 2012..

BACON, Francis. Nova Atlântida. Coleção os Pensadores. 2.ed. São Paulo: Abril Cultural, 1983.

BRASIL. Constituição da República Federativa do Brasil. 05 de outubro de 1988. Disponível em: <http:/ /www.planalto.gov.br/ccivil_03/constituicao/constitui\%C3\%A7ao.htm>. Acesso em: 9 nov. 2012.

COELHO, France Maria Gontijo. A arte das orientações técnicas em campo. Viçosa. UFV, 2005.

DESCARTES, René. Discurso do Método. Disponível em: <http://br.egroups.com/group/acropolis/ >. Acesso em: 17 abr. 2010.

FREIRE, Paulo. Extensão ou comunicação? São Paulo: Paz e Terra. 2006.

GUSTIN, Miracy B. S. As necessidades humanas e o (re)pensamento da ação universitária: a Interdisciplinar do Direito, Serviço de Assessoria Jurídica Universitária Popular da Faculdade de Direito da UFRGS. In: Edição Especial, n. 5. Porto Alegre: Faculdade de Direito da UFRGS, 2006.

LELIS, Davi Augusto Santana de; COELHO, France Maria Gontijo; DIAS, Marcelo Miná. A necessidade das intervenções: Extensão Rural como serviço ou como direito? In: Interações: Revista Internacional de Desenvolvimento Local. v. 13 n.1 p. 69-80. jan./jun 2012. Disponível em: <http:/ /www.ucdb.br/SII/mdl/filestorage/uploads/847.pdf>. Acesso em: 9 nov. 2012.

MACEDO FILHO, Renato; REGINO, Fabiene Alves. O empoderamento das mulheres do sertão: uma experiência do associativismo e desenvolvimento rural. In: RIMISP Centro Latino Americano para el Desarrollo Rural. Disponível em: <http://www.rimisp.org/getdoc.php?docid=6513>. Acesso em: 20 nov. 2012. 
MAIA, Christianny Diógenes. Assessoria Jurídica Popular - Teoria e Prática Emancipatória. Dissertação de Mestrado submetida à Universidade Federal do Ceará - UFC, para obtenção do grau de Mestre em Ordem Jurídica Constitucional. Orientadora: Professora Ana Maria D'ávila Lopes. Fortaleza, 2006. Disponível em: <http://pt.scribd.com/doc/30857165/Assessoria-Juridica-PopularChristianny-Diogenes-Maia>. Acesso em: 11 nov. 2012.

MORIN, Edgar. Epistemologia da tecnologia. O desafio da complexidade. In: Ciência com consciência. Rio de Janeiro. Bertrand Brasil, 2005.

PLATÃO. A república. Livro VII. Brasília: UnB/Ática, 1989.

RIBAS, Luiz Otávio. Assessoria Jurídica Popular Universitária. In: Captura Críptica: direito, política, atualidade. Revista Discente do Curso de pós-graduação em Direito. - n.1. v.1. (jul/dez 2008) - Florianópolis, Universidade Federal de Santa Catarina. Disponível em: <http:// www.ccj.ufsc.br/capturacriptica/documents/n1v1/parciais/ribas2.pdf>. Acesso em: 10 nov. 2012.

ROMANO, Jorge O.; ANTUNES, Marta. (Org.). Empoderamento e direito no combate a pobreza. Rio de Janeiro: ActionAid, 2002.

WOLKMER, Antonio Carlos. Pluralismo Jurídico: Fundamentos de uma nova cultura no Direito. 3. ed. São Paulo: Alfa Omega, 2001. Introdução ao Pensamento Jurídico Crítico. 4. ed. São Paulo: Saraiva, 2002.

\footnotetext{
${ }^{4}$ No âmbito da Universidade Federal de Viçosa, a AJUP constitui um projeto de extensão vinculado ao Observatório dos Movimentos Sociais. Atualmente, o projeto conta com financiamento de uma bolsa do Programa Institucional de Bolsas de Extensão Universitária da UFV (PIBEX).

${ }^{5}$ Empoderamento pode ser conceituado como um mecanismo de autonomia das pessoas, organizações e/ou comunidades inseridas em processos coletivos e sociais, que passam a controlar suas ações e decisões através da reivindicação de direitos e consciência de deveres. (MACEDO FILHO; REGINO, 2012, p. 1). Para melhor entender a temática do empoderamento, aconselha-se a leitura de ROMANO; ANTUNES (2002).

${ }^{6}$ Acerca do tema da Teoria Crítica do Direito, assevera Wolkmer (2002, p. 17-18): Distintamente do que é entendido por "teoria científica" como grau aceitável de objetividade, sistematicidade e universalidade, a "teoria crítica" torna-se importante na medida em que se atribui relevância ao sentido sociopolitico do Direito, ou seja, a plena eficácia a discurso que conteste o tipo de justiça apresentado por determinado ordenamento jurídico. Deve-se revelar uma formulação aceitável e satisfatória como discurso que aponte o sentido ideológico do Direito, na medida em que for responsável por prescrições normativas distorcidas das relações sociais. A estratégia não nega a "aparência real" do fenômeno jurídico, mas, sobretudo, procura revelar os interesses e as contradições que se ocultam por trás de uma estrutura normativa.

${ }^{7} \mathrm{O}$ pluralismo jurídico, como concepção filosófica, opõe-se ao "monismo" estatal. A este respeito, esclarece Wolkmer (2001, p. 171-172): Ao contrário da concepção unitária, homogênea e centralizadora denominada "monismo", a formulação teórica e doutrinária do "pluralismo" designa a 'existência de mais de uma realidade, de múltiplas formas de ação prática e da diversidade de campos sociais com particularidades própria, ou seja, envolve o conjunto de fenômenos autônomos e elementos heterogêneos que não se reduzem entre si.' O pluralismo enquanto concepção "filosófica" se opõe ao unitarismo determinista do materialismo e do idealismo modernos, pois advoga a independência e a inter-relação entre realidade e princípios diversos.

${ }^{8}$ Segundo Cappelletti e Garth, apud Abrão et al, (2009, p. 436), sucederam-se três momentos ou ondas como tentativas de concretizar o acesso à justiça, cada uma delas de acordo com a concepção histórica que se tinha do termo. Como primeira onda tem-se a assistência judiciária, que buscou mitigar os obstáculos econômicos de (in)acesso ao Poder Judiciário, atendendo especificamente às demandas das populações de baixa renda. Já pela segunda onda, pretendeu-se a representação dos interesses difusos, até que, finalmente, na terceira onda há completude articulada das duas primeiras. Para maiores detalhes, ver: CAPPELLETTI, Mauro \& GARTH, Bryant. Acesso à justiça. Trad. Ellen Gracie Northfleet. Porto Alegre: Safe, 1988.

${ }^{9}$ Essa mística engloba a quebra da formalidade presente nos serviços legais tradicionais, ao estabelecer uma relação de interação entre assessores e assessorados, complementada pela posição reivindicatória e participativa da comunidade. Ademais, supera a prática jurídica afastada da realidade social (MAIA, 2006, p. 88). ${ }^{10}$ A ética comunitária caracteriza-se pela adoção da lógica de correção dos erros ou superação completa das economias de mercado (MAIA, 2006, p. 90).

${ }^{11} \mathrm{O}$ termo utilizado se refere ao encantamento da lei, a compreensão de que o Direito já está completo e pode resolver tudo, nos moldes tradicionais (MAIA, 2006, p. 89).

${ }_{12}$ Campilongo apud Maia mostra que a postura ética dos serviços legais tradicionais é baseada em uma conduta cimentada com a consolidação das economias de mercado: individualismo, concorrência, calculabilidade econômica, não intervenção do Estado na economia, separação entre Estado e sociedade. (MAIA, 2006, p. 90)

${ }^{13}$ A Novelis é uma empresa com origem nos Estados Unidos. Em 2007 foi comprada pela Aditya Birla Group, um conglomerado multinacional com sede na Índia, tornando-se a maior empresa de laminação de alumínio do mundo, e uma das maiores produtoras de alumínio primário da Ásia. A Novelis opera fábricas em 11 países e teve receita informada de US\$10,6 bilhões em 2011.

${ }^{14}$ O MAB é um movimento nacional, autônomo, de massa, de luta, com direção coletiva em todos os níveis, com rostos regionais, sem distinção de sexo, cor, religião, partido político e grau de instrução. É um movimento popular, reivindicatório e político. Visa garantir os direitos das populações atingidas por barragens, a construção de um modelo energético popular e contribuir para construção de uma nova ordem social onde não haja divisão de classes.

15 Após as mobilizações populares foram reconhecidos 635 atingidos: 426 diaristas; 27 extratores de areia; 79 garimpeiros; 12 trabalhadores permanentes; 24 Após as mobilizações populares foram reconhecidos 635 atingidos
meeiros; 7 proprietários; 9 herdeiros; 51 artesãos de pedra sabão.

${ }_{16}$ Embora ora divididos em classes, importante destacar que os direitos humanos constituem uma categoria una e indivisível de direitos. Dessa forma, a divisão tal como proposta neste trabalho - e realizada durante o processo de confecção do relatório - teve finalidades essencialmente metodológicas, de molde a facilitar a compreensão e a tornar mais contundente as violações que se pretendeu comprovar.
} 